\title{
Varying temporal and spatial effects of climate on maize and soybean affect yield prediction
}

\author{
Gen Sakurai*, Toshichika Iizumi, Masayuki Yokozawa \\ National Institute for Agro-Environmental Sciences, 3 - 1 - 3 Kannondai, Tsukuba 305-8604, Japan
}

\begin{abstract}
The relationship between climatic factors and crop yields for maize and soybeans in 3 major producing countries (the United States, Brazil, and China) was analyzed statistically. Temporal changes in the climate-yield relationship were considered, and the temporal and spatial variations were evaluated. County-level data from 1980 to 2006 were collected for each country and allocated to $1.125^{\circ} \times 1.125^{\circ}$ grids. Data were analyzed for temporal changes in the effect of climate on yields using the particle filtering method for each grid. The 'current' effect of temperature on crop yields was shown to be geographically symmetric around the optimal temperatures $\left(19.51^{\circ} \mathrm{C}\right.$ for maize and $20.66^{\circ} \mathrm{C}$ for soybeans) in the Northern Hemisphere. In the Southern Hemisphere, the 'current' effect of precipitation was more influential than that of temperature. The effects of these climatic factors changed over time. Whereas the negative effect of high temperatures has been mitigated around the corn belt of the United States during the last 3 decades, it has intensified in Brazil, northern China, and the southern United States for maize. Consequently, predicted future yields differed marginally depending on the relationship (past or current effect) used for the prediction, even when they were summarized on country scales. This study suggests that temporal changes in the relationship between weather and crop yields should be considered for better future predictions.
\end{abstract}

KEY WORDS: Crop yields $\cdot$ Climate change $\cdot$ Data assimilation $\cdot$ Particle filtering method $\cdot$ Maize $\cdot$ Soybeans Resale or republication not permitted without written consent of the publisher

\section{INTRODUCTION}

With a growing global population and a changing climate, the need to examine the relationship between weather and crop production is increasingly important. The world population is predicted to exceed 9 billion by 2050 (DESA 2009), an increase of approximately $30 \%$ over the current population of 6.9 billion (US Census Bureau 2010). In addition to the growing population, improved standards of living and increasing economic activity in the developing world could increase food demand by $30 \%$ (Mann 1999, Rosegrant \& Cline 2003). Mounting evidence that increasing greenhouse gas concentrations are changing the global climate and precipitation patterns (IPCC 2007) indicates that the future of food security could be increasingly uncertain. Thus, before more elaborate process-based models are adop- ted to estimate future food production, the potential effect on crop yields of individual climatic factors, such as temperature and precipitation, should be estimated.

Although many studies have evaluated the effects of climate change on crop yields (e.g. Lobell \& Asner 2003, Fischer et al. 2005, Parry et al. 2005, Porter \& Semenov 2005, Mall et al. 2006, Lobell \& Field 2007, Lobell et al. 2007, 2008, Schlenker \& Roberts 2009), few studies have considered temporal variability in the relationship between weather and crop yields. During the last quarter of a century, agricultural techniques, such as specialized crop cultivars and irrigation systems, have changed dramatically. Compared to more recent cultivars, those developed in the early 1980s may respond differently to temperature fluctuations, indicating that the relationship between weather and crop yields can change over time. Thus, 
when analyzing the effects of climate change on crop production, methods that consider temporal changes in the relationship between weather and crop yields should be used.

In this study, we statistically estimated the timeseries changes in the relationship between climatic factors and crop yields for a large area $\left(1.125^{\circ} \times\right.$ $1.125^{\circ}$ latitude by longitude) using a data assimilation method known as particle filtering (Candy 2009). Using observed data, this method allowed us to estimate the time sequences of hidden parameters (in this case, the degree of the effect of climatic factors on crop yields) for each $1.125^{\circ} \times 1.125^{\circ}$ grid.

The target crops were maize and soybeans, and 3 countries, the United States, Brazil, and China, were considered. These crops are staple foods in the global diet, as well as important sources of animal feed and feedstock for bioethanol plants. In 2008, these 3 countries accounted for 65.40 and $67.55 \%$ of the world production of maize and soybeans, respectively (FAO 2010). Quantitatively evaluating the effects of climatic factors on these crops is essential to ensuring future food security.

Based on our analysis, we generated maps of the 'current' effects of weather on crop yields; and to evaluate the effect of temporal variations on the relationship between weather and crop yields in estimations of future productivity, we compared the effect on crop yields as estimated by the 'past' relationship between weather and crop yields with the effect estimated by the 'current' relationship. The simple structure of the statistical models used in this study allowed us to separate the climate effect into several climatic factors and to evaluate the relative effect of each factor on yields.

\section{DATA AND METHODS}

\subsection{Data}

We prepared yield data for maize and soybeans for the United States (county level, years 1980 to 2006), Brazil (municipal level, years 1990 to 2006), and China (county level, years 1980 to 2005). Data were obtained from the United States Department of Agriculture (USDA) (http://www.usda.gov/wps/portal/ usda/), the Brazilian Institute of Geography and Statistics (http://www.ibge.gov.br/home/), and the National Bureau of Statistics of China. Although the yield data for China covered only 4 provinces (Heilongjiang, Henan, Liaoning, and Shandong), maize and soybean production in these provinces accounts for approximately $40 \%$ and $51 \%$, respectively, of net production in China (USDA 1997).

For temperature $\left({ }^{\circ} \mathrm{C}\right)$ and precipitation $\left(\mathrm{mm} \mathrm{d}^{-1}\right)$ data, we used the Japanese Re-Analysis dataset (Onogi et al. 2007), which covers regions across the globe at a spatial resolution of $1.125^{\circ} \times 1.125^{\circ}$ (latitude by longitude). This grid scale was used as the basic scale for all analyses. We estimated the crop yields of each grid point by averaging the yield data of the counties (municipalities in Brazil) included in the grid. As some grid points were missing a large number of yield values, we only used grid points with $>14 \mathrm{yr}$ of yield data and no more than 3 continuous years of missing data. This resulted in 1264 grid points for maize and 666 grid points for soybeans.

The growing season (d) of each grid point was defined as the period from planting to harvest and was selected according to the Crop Calendar Dataset (Sacks et al. 2010) of the Center for Sustainability and the Global Environment (SAGE). Daily temperature and precipitation during the growing season were averaged for each year and each grid point.

\subsection{Detrending}

In all 3 countries, the crop yields have increased during the past 3 decades. Although the exact factors producing such trends are unknown, it is reasonable to assume that these include non-climatic factors. Therefore, we had to carry out detrending for yield data and climate data, and analyze the covariance between the deviations of yield and climate (temperature and precipitation) to eliminate non-climatic factors. These detrended data consisted of the residuals from the local regression model that was estimated for each grid point. In the local regression analysis, the degree of the polynomials was unity and we used the Gaussian function as the weight function (Cleveland et al. 1992).

Although we could arbitrarily decide the degree of smoothing (bandwidth or smoothing parameter) in the local regression analysis, we logically estimated the bandwidth of local regression model for each grid assuming that the shape of the yield trend for each grid point resembled that of the state (states in Brazil and provinces in China) to which the grid point belonged. This is because the pace of agricultural innovation was expected to be similar for regions in the same state. According to this assumption, the bandwidth that minimized the root mean square error (RMSE) between the model estimation and the state mean was selected for each grid point. The same 
bandwidth was used for the climate data for each grid point (Yamamura et al. 2006). Additionally, because the absolute values of the yield residuals tended to increase according to their yield, the yield residuals were adjusted by dividing the estimated yield into residuals. That is, relative errors were used for yield data.

\subsection{Particle filter}

We applied a particle filtering method with a selforganizing state-space model (Kitagawa 1998) to estimate the temporal change of the effect of climatic factors on crop yields. In the particle filtering method, the posterior distributions of parameters (the effect of temperature or precipitation in this study) at time $t$ are sequentially estimated using Bayesian statistics, where the distributions of the parameters at time $t-1$ are used as the prior distributions. The distributions of parameters are approximated by a large number of 'particles'. Therefore, we can assume non-Gaussian distribution for the error distribution.

Firstly, in the particle filtering method, the system equation and the observation equation should be defined. The system equation is the statistical model that describes the transition process of state variables (the effect of temperature or precipitation in this study) from time $t-1$ to time $t$. The observation equation is the statistical model that describes the relationship between the state variables and the observation variables. At time $t$, we generate the proposal distributions from the distributions of the state variables at time $t-1$ according to the system equation (the distribution is approximated by particles). Then, we estimate the observation variables according to the observation equation, and weight each particle according to the likelihood calculated by the actual observation value at time $t$. By re-sampling the particles according to the weightings, we can obtain the posterior distributions of the state variables at time $t$. The temporal changes of the state variables can be obtained by repeating this procedure.

The system and observation equations were defined, respectively, as follows:

$$
\begin{gathered}
Z_{t}=Z_{t-1}+\varphi_{s}, \quad \varphi_{s} \sim N(0, \Theta) \\
Y_{t}=C_{t-1} \cdot Z_{t}^{T}+\varphi_{o}
\end{gathered}
$$

where $Z_{t}$ is an unknown $2 \times 1$ state vector at year $t_{i} \varphi_{s}$ is a $2 \times 1$ system noise vector that follows a bivariate normal distribution with variance-covariance matrix $\Theta_{i} Y_{t}$ is the observed yield value at year $t$ that was detrended; $C_{t}$ is a $2 \times 1$ vector containing observed climate data that was detrended; and $\varphi_{o}$ is the observation error. Here, $\mathrm{T}$ denotes the transpose of the matrix. A normal or Gumbel distribution was used to represent the observation error distribution: The AIC (Akaike's information criterion) values of the models that have normal distribution and Gumbel distribution were calculated, respectively, and the model with the lower AIC was selected for each grid point. As the non-informative prior distribution of $Z_{t}$, we used uniform distribution with an adequate range. The estimated time-series behavior of $Z_{t}$ in Eqs. (1) \& (2) indicates the time-series behavior of the degree to which temperature and precipitation affected crop yields: this represents the relationship between climatic factors and yields at time-step $t$. If the estimated value of the $Z_{t}$ vector at a given year in a given grid point is negative, an increase in the mean temperature (or precipitation) during the growing season causes a decrease in the average yield and vice versa. Smoothing was achieved using the backward smoothing technique in which the particle filtering algorism was repeated inversely (from $t=\mathrm{N}$ to $t=1$ ) so that the information between $t=i+1$ and $t=\mathrm{N}$ is also reflected in the result of $t=i$ (Candy 2009).

In the particle filtering method, the value of $\Theta$ in Eq. (1) restricts the range in which the value of $Z_{t}$ can change in each time step, which will affect the timeseries behavior of $Z_{t}$. In the self-organizing statespace model, we can also estimate the distribution of $\Theta$ together with $Z_{t}$ by importance sampling. We first generated the proposal distribution of $\Theta$ using the following method.

Before implementing the particle filtering method, we fitted multiple linear regression models to the yield data of each grid point. In the full model, the dependent variable was detrended yields $(\delta y)$, and the independent variables were detrended temperature $(\delta t m)$, the detrended precipitation $(\delta p r)$ and their interactions with the time series ( $\delta t m$ : $t$ and $\delta p r: t$ ). The interaction terms were interpreted as the annual rate of change in the effect of temperature and precipitation on yield when assuming a linear change in the effect of climate. To avoid multicollinearity, the interaction terms were excluded from the full model when the variance inflation factor (VIF) exceeded 10. We estimated each coefficient using Bayesian model averaging (BMA) with Bayesian Information Criterion (BIC) approximation (Raftery 1995). The prior weight of each variable was 0.5 . If the $1 \mathrm{yr}$ lag correlation of the residuals of the averaged models was significant at the 0.05 level (Ljung-Box test) (Box \& Pierce 1970), the term of the $1 \mathrm{yr}$ correlation $\left(\delta y_{t-1}\right)$ 
was added to the full model and recalculated. Thus, the full model was expressed as follows:

$$
\begin{aligned}
\delta y_{t}= & \alpha_{1} \cdot\left(\delta y_{t-1}\right)+\alpha_{2} \cdot \delta t m_{t}+\alpha_{3} \cdot \delta p r_{t} \\
& +\alpha_{1} \cdot\left(\delta t m_{t}: t\right)+\alpha_{3}\left(\delta p r_{t}: t\right)+\varepsilon_{t}, \varepsilon \sim N\left(0, \sigma^{2}\right)
\end{aligned}
$$

where $\alpha_{1-5}$ denote the regression coefficients, $\varepsilon$ denotes errors that follow a normal distribution with variance $\sigma^{2}$, and $t$ denotes the time (yr). In Eq. (3), the values of $\alpha_{4}$ and $\alpha_{5}$ can be interpreted as the change rates of the effect of $\delta t m_{t}$ and $\delta p r_{t}$. Therefore, we used the distributions of $\alpha_{4}$ and $\alpha_{5}$ as the proposal distributions of non-diagonal elements of $\Theta$ in the particle filtering method. Additionally, the RMSE of the estimated yield was used as the variance of the error term of Eq. (2), or $\varphi_{o}$. We generated the spatial distributions of 'current' effect of climatic factors on crop yield (see Fig. 1) by using the mean values of the posterior distributions estimated from the particle filtering method.

\subsection{Future estimation}

The predicted impact of future climate change on the yields of maize and soybeans was calculated by using both the past ( $t=1980$ or 1990 for Brazil) and current $(t=2006)$ values of the coefficients $\left(Z_{t}\right)$ estimated in the particle filtering method, and the differences in the predictions were compared. The values of the estimated coefficients $\left(Z_{t}\right)$ were randomly sampled (300 samples) from the posterior distribution of each grid. Future climatic values from the MIROC 3.2 (A1B scenario) model were applied to the coefficients, and the predicted yields for each grid were calculated. The values used for the future climates were the average temperatures and daily precipitation during the periods 2012-2016, 2022-2026, 2032 2036, and 2070-2099. The total predicted crop production for each country was calculated by summing the crop production of each grid, which was weighted according to the grid area and the harvested area of maize and soybeans (Monfreda et al. 2008). This procedure was repeated 300 times, and the distribution of the predicted change (\%) in total crop production from the current production (from 2002 to 2006) was calculated for each country, future period, and coefficient set.

\subsection{Relative effects of temperature and precipitation}

To evaluate the relative impact of temperature and precipitation factor on yield, the determination coeffi- cient of each climatic factor was calculated for each grid point. To calculate this value, the following equations were used:

$$
\begin{aligned}
& \mathrm{R}_{t m}^{2}=1-\frac{\Sigma_{t}\left(y_{t}-\widehat{y_{t m_{t}}}\right)^{2}}{\Sigma_{t}\left(y_{t}-\bar{y}\right)^{2}} \\
& \mathrm{R}_{p r}^{2}=1-\frac{\Sigma_{t}\left(y_{t}-\widehat{y_{p r_{t}}}\right)^{2}}{\Sigma_{t}\left(y_{t}-\bar{y}\right)^{2}}
\end{aligned}
$$

where $\mathrm{R}_{t m}^{2}$ and $\mathrm{R}_{p r}^{2}$ indicate the determination coefficient of temperature and precipitation, respectively; $y_{t}$ is the observed yield (detrended) at year $t_{\text {; }}$ $\bar{y}$ is the average of $y_{t i} \widehat{y_{t m_{t}}}$ is the estimated yield at year $t$ from the statistical model in which precipitation had no effect; and $\widehat{Y_{p r_{t}}}$ is the estimated yield at time $t$ from the statistical model in which temperature had no effect.

All analyses were performed with $\mathrm{R}$ version 2.10.0 (R Development Core Team 2009). For the BMA analysis, the bic.glm function of the BMA package version 3.12 of $\mathrm{R}$ was used.

\section{RESULTS}

\subsection{Current effects of climate}

Fig. 1a,c are maps of the 'current' effect of temperature on crop yields showing the estimated degree to which average temperature influenced yields of maize and soybeans in the mid-2000s $(5 \mathrm{yr}$ average from 2002 to 2006). Similar geographical patterns were estimated for both maize and soybeans. Based on an increase in average temperatures, the region where estimated yields decreased was separated from the region where yields increased at approximately $40^{\circ} \mathrm{N}$. The average temperature at this latitude during the growing season was roughly $20^{\circ} \mathrm{C}$.

Fig. $1 \mathrm{~b}, \mathrm{~d}$ are maps of the 'current' effect of precipitation on crop yields showing the estimated degree to which average daily precipitation influenced yields in the mid-2000s. For both maize and soybeans, similar patterns of the effects of precipitation were estimated. In nearly all regions of the United States, an increase in average precipitation during the growing season increased average yields. In Brazil, a slightly negative effect was estimated in central regions, whereas positive effects were estimated in the other regions. In China, negative effects were estimated in the northern region and positive effects were estimated around Liaoning province. 

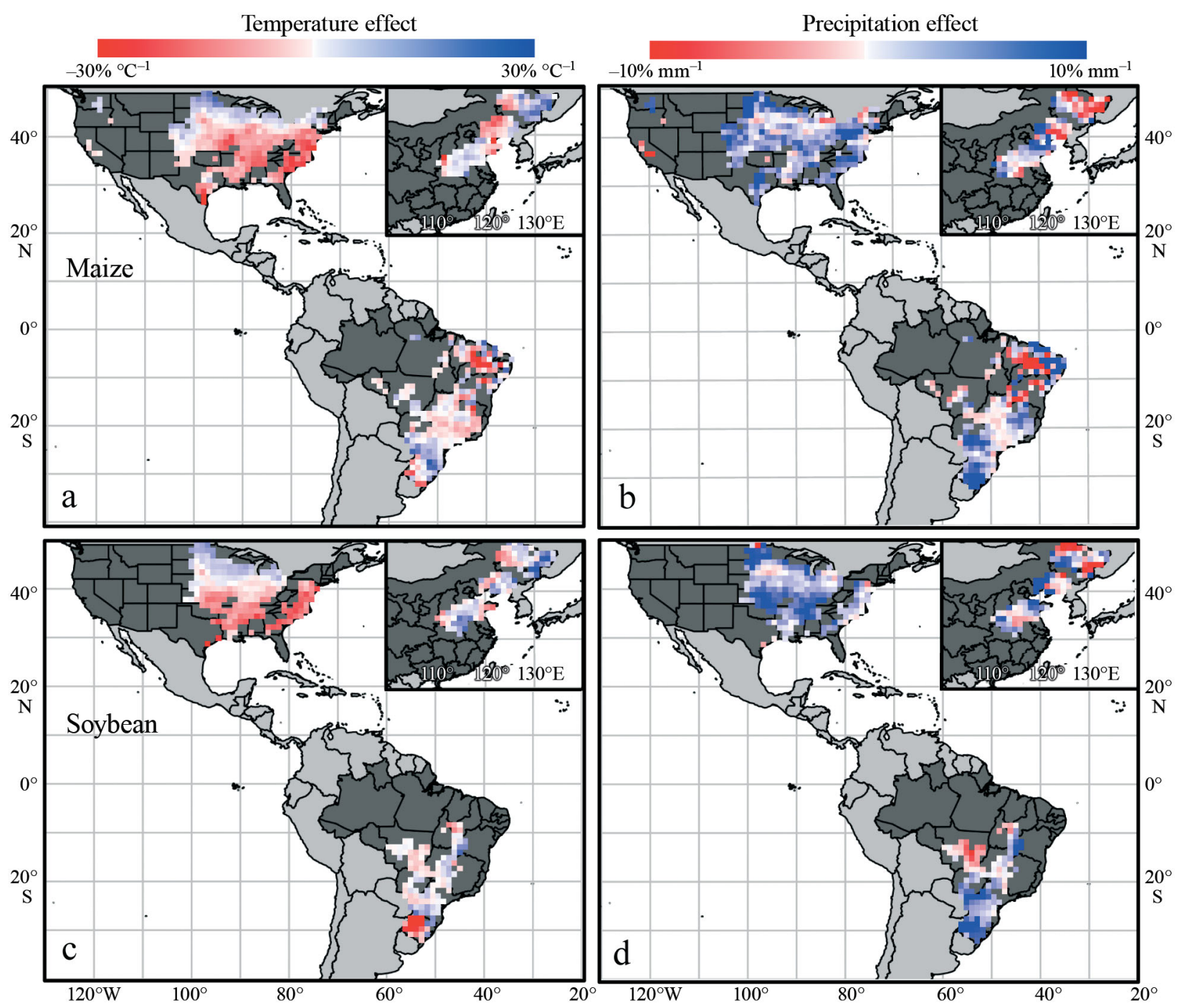

Fig. 1. 'Current' effects of temperature and precipitation on $(a, b)$ maize and $(c, d)$ soybean yields. $(a, c)$ Temperature effects, $(b, d)$ precipitation effects: colors indicate the estimated gain in yield (\%) when the average temperature (average daily precipitation) during the growing season increases by $1^{\circ} \mathrm{C}$ (increases by $1 \mathrm{~mm}$ )

\subsection{Time-series changes in the relationship between weather and yields}

To determine whether the relationship between climatic factors and crop yields changed significantly over time in each grid point, the Mann-Kendall test was used on the time sequences of average $Z_{t}$ for each grid point (Fig. 2). The Mann-Kendall test is a nonparametric test to detect the time-series trend of data. If the result of the Mann-Kendall test is significant, it means that the time-series variables have an increasing or decreasing trend. In many grid points, the results were significant. For maize, the results for 494 out of 1264 grid points and 498 out of 1264 grid points were significant $(\mathrm{p}<0.05)$ for temperature and precipitation, respectively. For soybeans, 257 out of 666 grid points and 226 out of 666 grid points were significant for temperature and precipitation, respectively. When a grid point showed no trend, the p-values followed a uniform distribution. However, the calculated distributions were significantly different from uniform distributions (Kolmogorov-Smirnov test with $\mathrm{p}<0.001$ ). Thus, these results suggest that the relationship between climatic factors and crop yields changed in many grid points.

Fig. 3 shows a map of changes in the relationship between temperature and crop yields from 1980 to 2006 (1990 to 2006 for Brazil). These maps were generated by calculating the difference between the values of the current and past temperature effects, or 


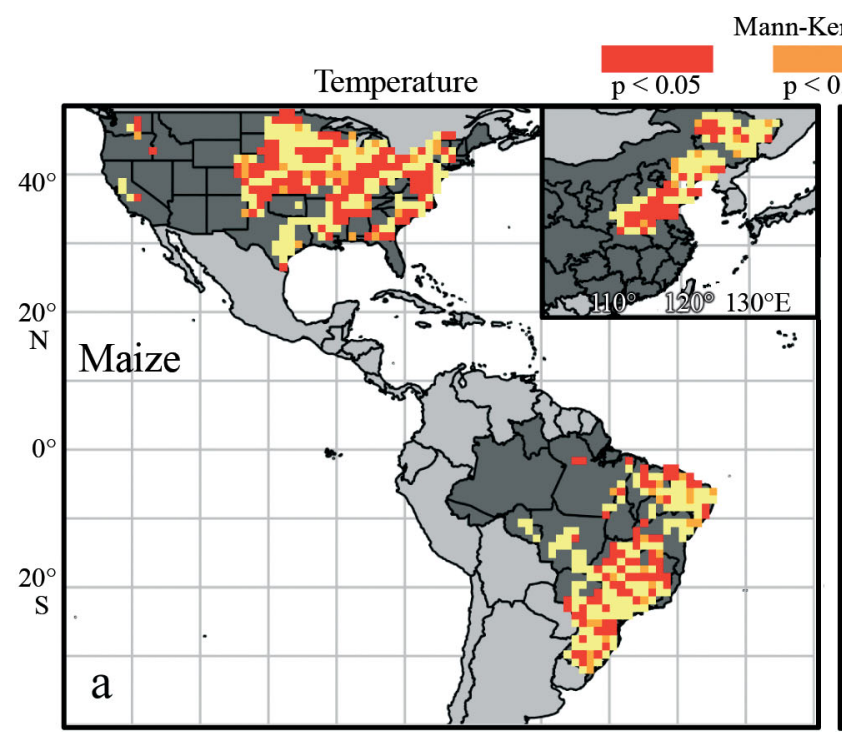
$\mathrm{p}<0.10 \quad 0.10>\mathrm{p} \quad$ Precipitation
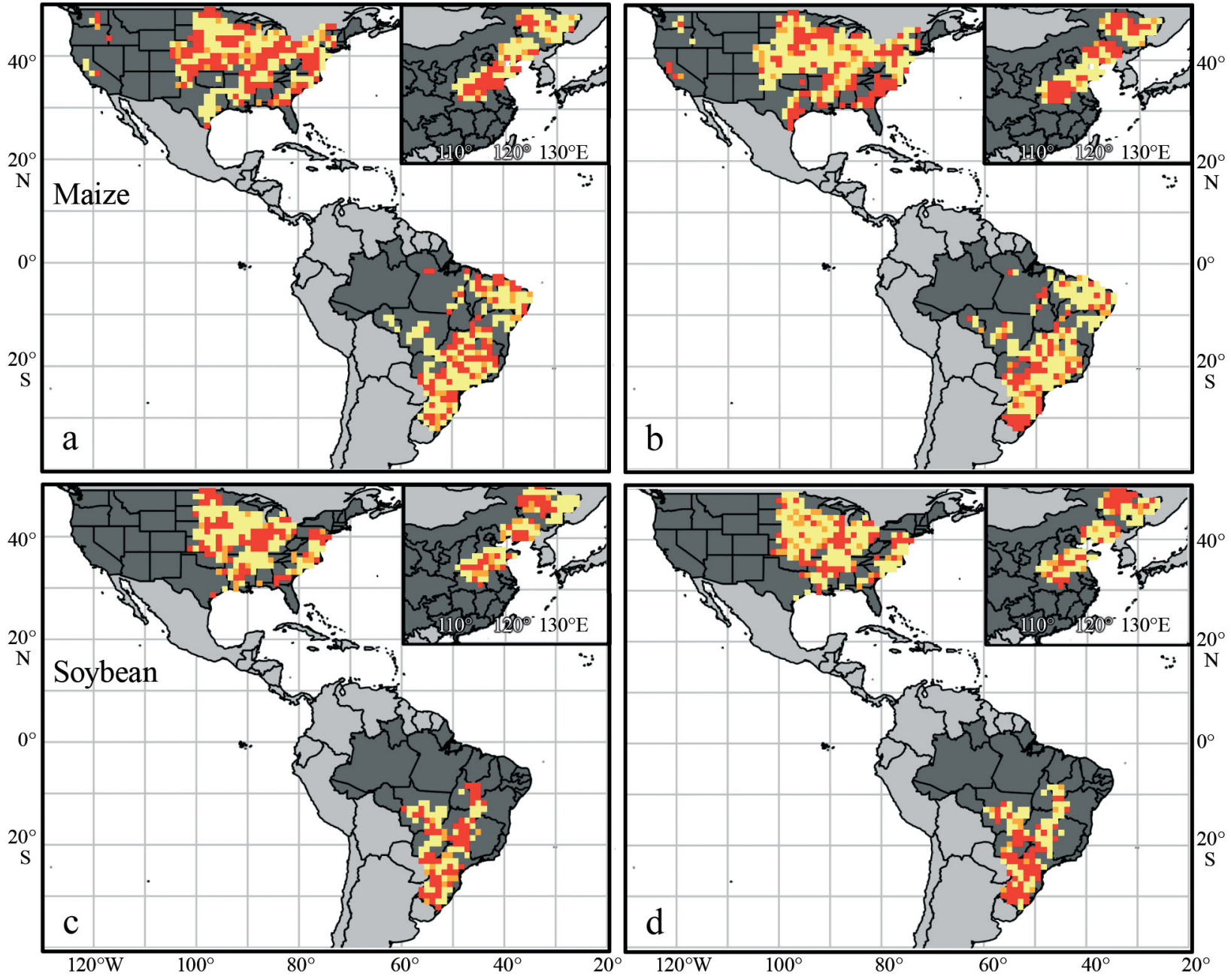

Fig. 2. The significant grid points of the Mann-Kendall test for $(\mathrm{a}, \mathrm{b})$ maize and $(\mathrm{c}, \mathrm{d})$ soybeans

$Z_{2006}-Z_{1980}$. Orange-colored areas indicate that crop yields are more sensitive to high temperatures in 'current' as opposed to 'past' times. Blue-colored areas indicate that the 'current' high temperature effect (Fig. 3a,c) or high precipitation effect (Fig. 3b,c) is reduced compared to 'past' times. For maize and soybeans, the negative high temperature effect was particularly reduced in the corn belt. The negative high temperature effect was slightly stronger in southern Brazil and China, particularly for soybeans.

\subsection{Future estimation}

Fig. 4 shows the predicted impact of climate change on crop yields based on the MIROC 3.2 climate model. The predictions show relative changes
$(\%)$ in total crop production from the average total production from 2002 to 2006 for each country, crop, and future period. The relationship between weather and yields used for the predictions $\left(Z_{2006}\right.$ or $\left.Z_{1980}\right)$ influenced the predictions, especially for maize and soybeans in the United States, where predictions obtained from current relationships $\left(Z_{2006}\right)$ had smaller negative impacts than those obtained from past relationships $\left(Z_{1980}\right)$ (Fig. 4a,b,e,f). In the United States, the probabilities that the production rate estimated from the past relationships were lower than those from the current relationships were 0.83 (0.78) for 2012 to $2016,0.85$ (0.74) for 2022 to 2026, 0.89 (0.81) for 2032 to 2036, and 0.86 (0.62) for 2070 to 2099 for maize (soybeans). In the other countries, the predicted differences were slight (Fig. 4c,d,g). However, in Brazil, the predictions obtained from the current 

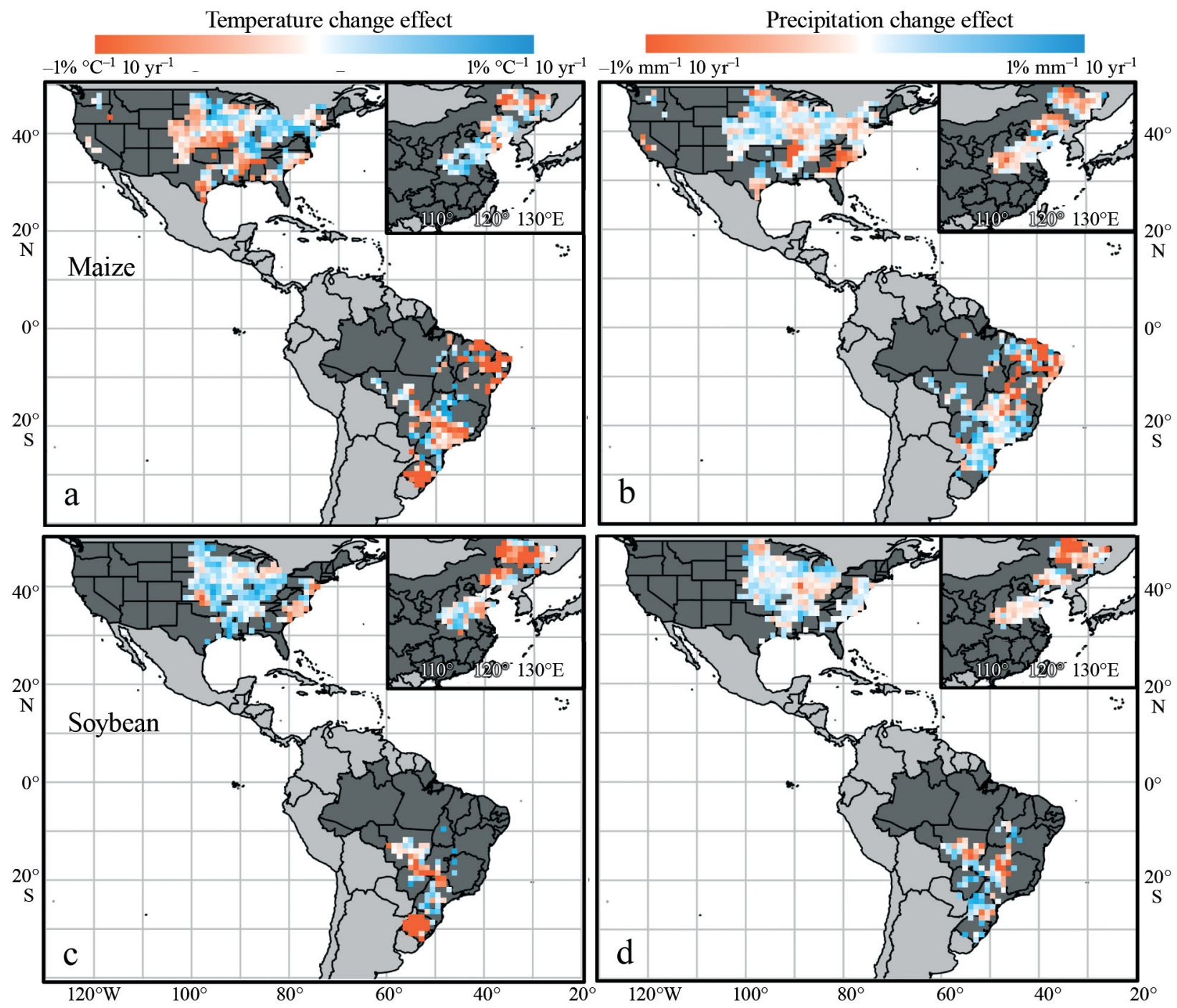

Fig. 3. Temporal change in the relationship between temperature or precipitation and crop yields for (a,b) maize and (c,d) soybeans. The colors indicate the estimated rate of change in the effect of temperature or precipitation from 1980 to 2006 (from 1990 to 2006 for Brazil). The rate of change was calculated by dividing the difference between the current (years 2002 to 2006) and past (years 1980 to 1984, but years 1990 to 1994 for Brazil) temperature or precipitation effects by the time span (27 yr for the United States and China and 17 yr for Brazil)

relationships had greater negative impacts than those obtained from past relationships (Fig. 4h): the probability that the estimates from the past relationships were higher than those from the current relationships was 0.87 for soybeans.

\subsection{Relative impacts of temperature and precipitation}

Fig. 5a shows the relative impact of temperature $\left(R_{t m}^{2}\right)$ on maize yields. For both maize and soybeans, similar geographical patterns were estimated (soybeans not shown). In the United States, the effect of temperature was substantial in the central and northern parts of the country (maize [mean $\pm \mathrm{SD}$ ]: $0.14 \pm$ $\mathrm{SD} 0.13$; soybeans: $0.18 \pm \mathrm{SD}$ 0.13). In Brazil, the effect of temperature was relatively small compared to the United States (maize: $0.02 \pm \mathrm{SD} 0.21$; soybeans: $0.02 \pm \mathrm{SD}$ 0.16). In China, the influence of temperature was relatively pronounced in the north (maize: $0.11 \pm$ SD 0.12; soybeans: $0.09 \pm$ SD 0.08).

Fig. 5b shows the influence of precipitation $\left(R_{p r}^{2}\right)$ on maize yields. Similar geographical patterns were estimated for both maize and soybeans (figure is omitted for soybeans). In the United States, the effect of precipitation was more pronounced in the southern part of the country (maize [mean $\pm \mathrm{SD}$ ]: $0.09 \pm 0.12$; soy- 


\section{MAIZE}

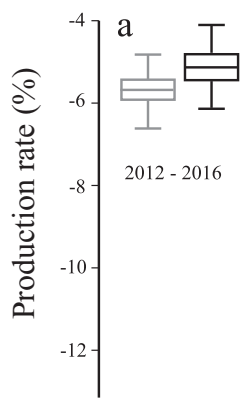

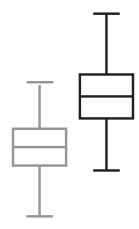

$2032-2036$

\section{SOYBEAN}

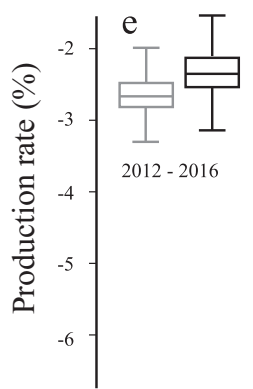

$\underset{2022-2026}{I}$

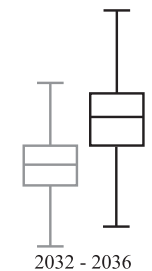

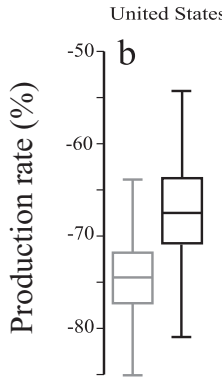

$2070-2099$

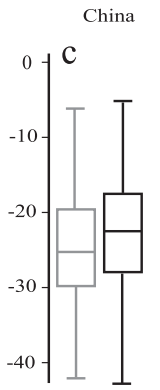

2070 - 2099

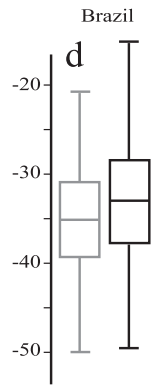

$2070-2099$

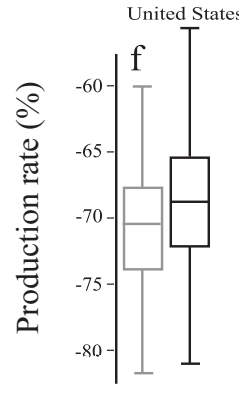

$2070-2099$

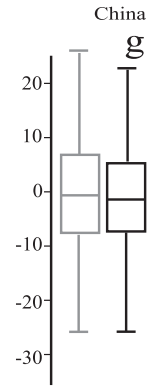

$2070-2099$

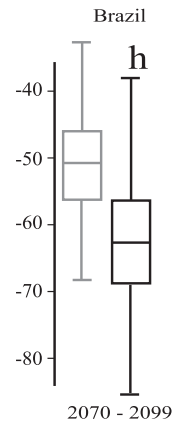

Fig. 4. Predicted change (\%) in total future production from total current (from 2002 to 2006) production for each country. The gray box-plots indicate the predicted change (\%) estimated from the parameter sets of the first time step, $Z_{1980}$ (past relationship between weather and yields estimated by the particle filtering method). The black box-plots indicate the predicted change (\%) estimated from the parameter sets of the last time step, $Z_{2006}$ (current relationship between weather and yields). (a,e) Weather-yield relationships from 2012 to 2016, 2022 to 2026 and 2032 to 2036 for the United States. (b-d, f-h) Weatheryield relationships from 2070 to 2099 for the United States, China, and Brazil. The box-plots were constructed by bootstrap sampling 300 samples from the posterior distribution. The lower, middle, and upper bounds of the boxes indicate the first, second, and third quartiles. The bars indicate maximum and minimum values

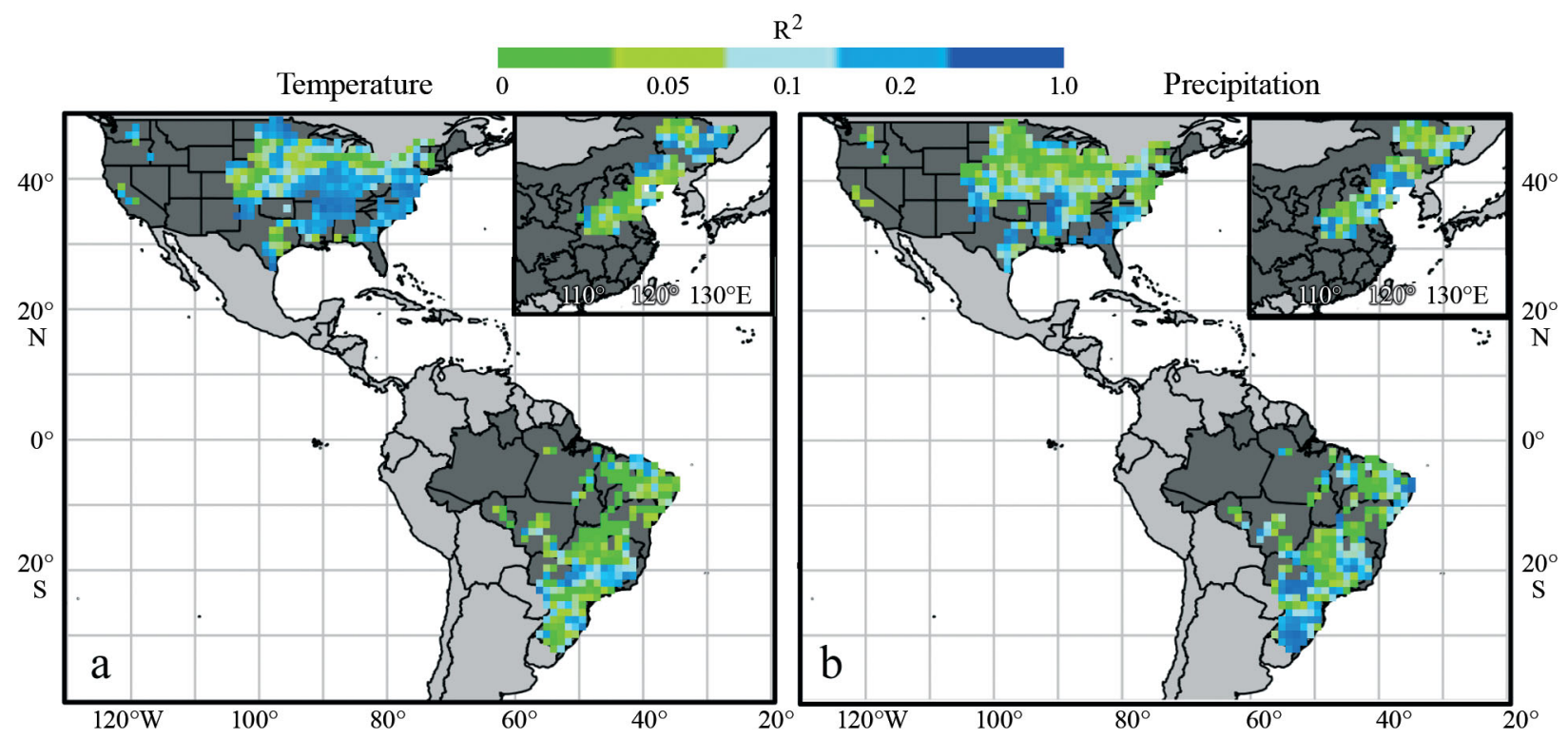

Fig. 5. The past impact of (a) temperature and (b) precipitation on yields of maize during the last quarter of a century (from 1980 to 2006). Colors indicate the estimated determination coefficient (from 0 to 1 ) for temperature and precipitation. If the determination coefficient is 0 , temperature or precipitation has no influence on crop yield. If the determination coefficient is 1 , the fluctuation in crop yield is affected by only temperature or precipitation 
beans: $0.11 \pm 0.12$ ) and the overall influence of precipitation was smaller than that of temperature for both maize and soybeans (Wilcoxon rank sum test, maize: $p<0.001$; soybeans: $p<0.001)$. In Brazil, the effect of precipitation was relatively greater in the south (maize: $0.04 \pm 0.23$; soybeans: $0.12 \pm 0.16$ ) and the overall influence of precipitation was greater than that of temperature (maize: $p=0.005$; soybeans: $\mathrm{p}<0.001$ ). In China, the influence of precipitation was relatively large, except for maize in Heilongjiang province. However, there was no clear pattern for soybeans (maize: $0.12 \pm 0.12$; soybeans: $0.12 \pm 0.12$ ). The overall influence of precipitation was not significantly different from that of temperature for maize $(p=0.56)$ and soybeans $(p=0.15)$.

\section{DISCUSSION}

\subsection{Spatial variation in the effects of climate}

Fig. 1 shows the degree to which temperature impacted crop yields changed along a geographical gradient: negative effects of high temperatures were estimated mainly in low-latitude regions, whereas positive effects were estimated mainly in high-latitude regions for both maize and soybeans. Negative and positive effects of temperature have been reported in many studies. Higher temperatures may accelerate crop development and reduce the duration of grain filling but extremely high temperatures during flowering can reduce grain or seed production (Cheikh \& Jones 1994, Wilhelm et al. 1999, Engelen-Eigles et al. 2000, Koti et al. 2007). Lower temperatures can reduce crop yields because of decreased crop growth or because of the increased risk of chilling injury (Baker \& Allen 1993, Thakur et al. 2010). The geographical gradient should reflect the optimum temperature of each crop.

The optimum average temperatures - defined as the average temperature during the growing season around which crops are not significantly affected by temperature changes - of maize and soybeans were estimated for each hemisphere. In the Northern Hemisphere, significant negative relationships between the effects of temperature and the average temperatures of the grid points for both maize and soybeans were found (robust regression with Tukey's bi-square, maize: $\mathrm{p}<0.001$; soybeans: $\mathrm{p}<0.001$ ), and the optimum average temperature (the intercept of the regression) was estimated to be $19.51 \pm 0.13^{\circ} \mathrm{C}$ (SE) for maize and $20.66 \pm 0.12^{\circ} \mathrm{C}$ for soybeans. Thus, regions where the average temperature is around $20^{\circ} \mathrm{C}$ are predicted to be resistant to future climate change. These results were consistent with the previous results of Schlenker \& Roberts (2009). They suggested that the critical threshold temperature above which the crop yield decreases sharply is $29^{\circ} \mathrm{C}$ for maize and $30^{\circ} \mathrm{C}$ for soybeans. In the Northern Hemisphere, the number of days on which the daily average temperature exceeds $29^{\circ} \mathrm{C}\left(30^{\circ} \mathrm{C}\right)$ increases sharply when the average temperature of the growing season is close to the optimum average temperature (around $20^{\circ} \mathrm{C}$ ) (Fig. 6). In the Southern Hemisphere, there was no such relationship for maize $(\mathrm{p}=$ $0.54)$ or soybeans $(p=0.68)$. This ambiguous geographical pattern could be explained by variability in Brazil's climate, which ranges from semi-arid to trop-
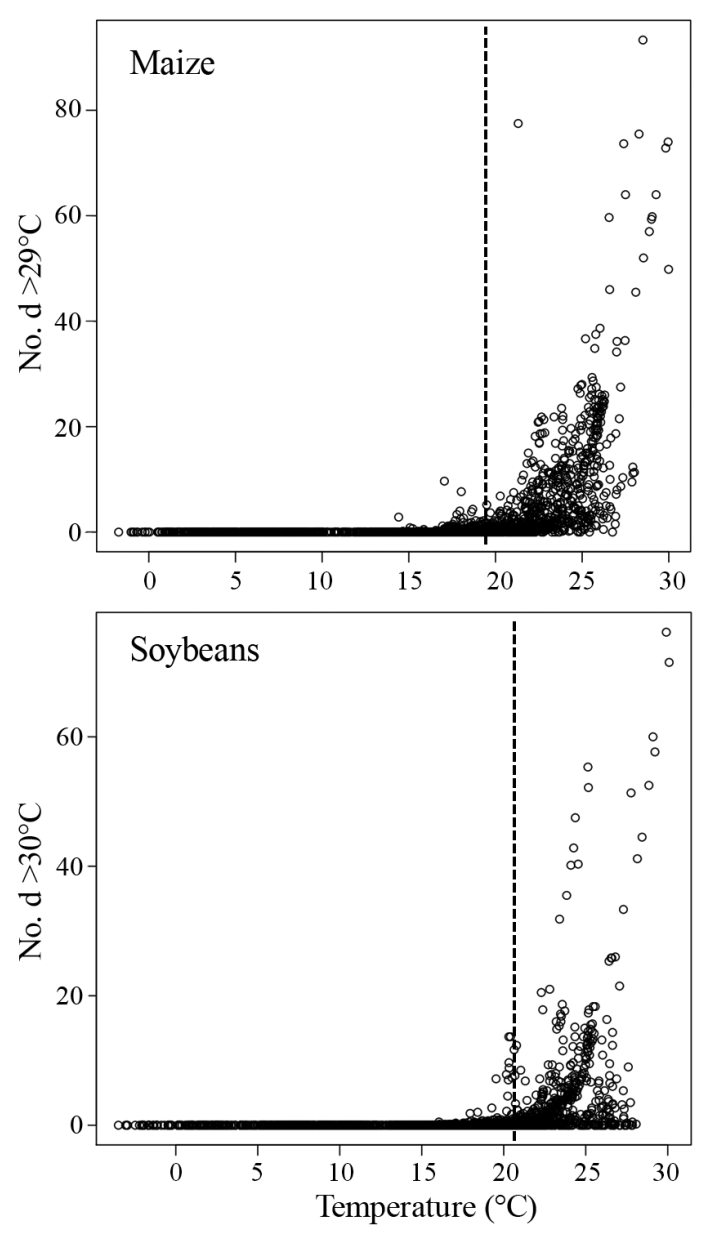

Fig. 6. The relationship between the average temperature during the growing season of (a) maize and (b) soybeans, and the number of days with temperatures $>29^{\circ} \mathrm{C}\left(>30^{\circ} \mathrm{C}\right.$ for soybeans) for each grid, in the USA and China. The values were estimated from the average during years 2002 and 2006. The threshold values $\left(29^{\circ} \mathrm{C}\right.$ and $\left.30^{\circ} \mathrm{C}\right)$ are based on the results of Schlenker \& Roberts (2009). Dashed lines: optimum temperatures for crops 
ical zones. Additionally, the strong effect of rainfall might have overwhelmed the effects of temperature.

Except for the regions around Heilongjiang province and the center of Brazil, precipitation exerted a positive effect in all areas (Fig. 1). In the aforementioned regions, the risk of floods may be associated with an increase in average precipitation. More detailed research is needed in these areas.

In this study, we assumed only a linear relationship between the average climatic conditions during the growing season and crop yields. If we considered extreme temperature or rainfall events, the results obtained would change to some extent (Schlenker \& Roberts 2009). However, as mentioned above, the results of the present study were consistent with the results of Schlenker \& Roberts (2009), in which daily extreme events were considered. Therefore, we could obtain appropriate results to some extent by only considering the average temperature or precipitation. Furthermore, we analyzed the effect of climate on crop yields for each grid in this study. Although implementing the spatial correlation into the particle filter would require enormous calculations, such expansion remains to be carried out in future work.

\subsection{Temporal variation in the effects of climate}

Have the effects of climatic factors on yields been constant during the past quarter of a century? In most grid points, the relationship between climatic factors and crop yields showed temporal variation, indicating that the climatic effects on yields have not been constant (Fig. 3). Schlenker \& Roberts (2009) reported no temporal variation in the relationship between weather and yields. In their study, temporal variation was evaluated by cross-sectional analysis. However, they did not consider 'the spatial variation of the temporal variation'. In the present study, the temporal variation of each grid point was analyzed, and significant temporal variations were found in many grid points (Fig. 2). We do not have a clear answer to why the effects of climatic factors on yields were temporally changed in some regions and not in the others. However, factors that have potentially changed the strength and direction of the effects of climatic factors on crop yields include the improvement of cultivars, cultivation management and/or the prevalence of irrigation systems. The reductions in the negative effect of high temperatures were observed particularly in the grids where the harvested areas were large, such as in the 'corn belt'. In the United States, the change rate of the effects of temperature was significantly (marginally significantly) correlated with the harvested area of the grids (maize: $p<0.001$, soybeans: $\mathrm{p}=0.16$ ). Similarly, it appears that the impacts of drought were reduced particularly, for example, around the Mississippi River where the irrigation system is widespread (Siebert et al. 2005) (see Fig. 3). This implies that, in the United States, the rate of the improvement of cultivar, cultivation management, or the irrigation system may be relatively high in the region where intensive cultivation or irrigation is carried out. A socioeconomic study may explain the spatial variation in the change rate in future studies. The most important point is that there were significant temporal changes in the effect of climate on crop yields in many regions. In previous studies, the relationships between climatic factors and crop yields were assumed to be constant over time (e.g., Lobell \& Asner 2003, Fischer et al. 2005, Parry et al. 2005, Porter \& Semenov 2005, Mall et al. 2006, Lobell \& Field 2007, Lobell et al. 2007, 2008). However, the present study demonstrates that the relationship between weather and yield is not constant. Thus, when predicting future effects of climate on yields, the temporal dynamics of parameters should be considered, and current estimations of parameters should be used.

\subsection{Future predictions}

Yields estimated from 'current' (2006) relationships between weather and crop yields were marginally different from those estimated from 'past' (1980) relationships. The difference was particularly large (approximately 10\%) in the United States from 2077 to 2099 (Fig. 4). This prediction was the sum of predictions for the whole grid, and as mentioned above, there was spatial variation in the temporal variation between grid points. Thus, differences may be larger when values are estimated for each grid point. Similarly, in China and Brazil, small differences in the predictions between 'past' and 'current' parameter sets were attributed to the spatial pattern of temporal variations in climatic effects (Fig. 3). Although spatial variation among the regions would be balanced when evaluating the difference between future predictions made using the 'past' and 'current' parameter sets at a country scale, the variation would stand out when comparing predictions at smaller scales (see Fig. 3).

The fertilizer effect of $\mathrm{CO}_{2}$ was not considered in this study. Although many studies have tried to estimate this effect, reported values differ slightly. For C3 plants like soybean, the estimated values are dis- 
tributed around a 10 to $20 \%$ increase when the concentration of $\mathrm{CO}_{2}$ is approximately $550 \mathrm{ppm}$. For $\mathrm{C} 4$ plants like maize, the estimated values are distributed around a $10 \%$ increase (e.g. Leakey et al. 2004, Long et al. 2004, Ainsworth et al. 2008). The $\mathrm{CO}_{2}$ effect will change the predicted crop production, but the relative difference in the predictions using 'past' versus 'current' parameter sets should not differ. Furthermore, in this study, nonlinear relationships between weather and crop yields (Schlenker \& Roberts 2009) were not considered. Future studies need to analyze the relationship between climatic factors and crop yield using a non-linear model with the particle filtering method in future studies. In addition, we used the output of a single General Circulation Model (GCM), whereas better predictions would be obtained using multiple GCMs and a variety of cultivation management patterns. This is an important task to be carried out in future studies involving statistical analysis of temporal changes in the climatic effect on crop yield.

\subsection{Past influence of climatic factors}

The past influence of each climatic factor was also estimated (Fig. 5). In the United States, on average, crops were more affected by temperature than by precipitation during the last quarter of a century. In Brazil, crops were more affected by precipitation than by temperature during the same period. This difference could be explained by the prevalence of irrigation systems (Siebert et al. 2005); enhanced irrigation systems in Brazil could improve potential yields. However, regions that were strongly affected by precipitation were located in areas where irrigation systems were relatively prevalent (Siebert et al. 2005). Thus, the security of water resources in these regions could impact crop yields.

\section{CONCLUSIONS}

We statistically estimated the current effect of temperature and precipitation on the yields of maize and soybeans in 3 countries (the United States, Brazil, and China) by using the particle filtering method. In the Northern Hemisphere, on average, temperature had a larger influence on yields than precipitation, and the degree to which temperature affected yields showed a geographically symmetric pattern around the optimal temperatures $\left(19.51^{\circ} \mathrm{C}\right.$ for maize and $20.66^{\circ} \mathrm{C}$ for soybeans). In the Southern Hemisphere, on average, precipitation had a larger influence on yields than temperature. The effect of the climatic factors significantly changed throughout the time series, suggesting that methods that account for temporal variations in parameters, such as the particle filtering method, are needed to evaluate and estimate the future impact of climatic factors on crop yields.

Acknowledgments. This study was supported by the Innovative Program on Climate Change Projection for the 21st Century (KAKUSHIN Program), Japan. This study was also conducted under the auspices of The Institute for Statistical Mathematics (ISM) Cooperative Research Program (2010-ISM-CPP-1005). We are grateful to Drs. S. Nakano and G. Ueno of ISM for valuable advice on the Monte Carlo simulation.

\section{LITERATURE CITED}

Ainsworth EA, Leakey A, Ort D, Long S (2008) FACE-ing the facts: Inconsistencies and interdependence among field, chamber and modeling studies of elevated $\left[\mathrm{CO}_{2}\right]$ impacts on crop yield and food supply. New Phytol 179:5-9

> Baker J, Allen L (1993) Contrasting crop species responses to $\mathrm{CO}_{2}$ and temperature: rice, soybean and citrus. Plant Ecol 104-105:239-260

Box GEP, Pierce DA (1970) Distribution of residual correlations in autoregressive-integrated moving average time series models. J Am Stat Assoc 65:1509-1526

Candy JV (2009) Bayesian signal processing: classical, unscented and particle filtering methods. John Wiley, New York, NY

Cheikh N, Jones RJ (1994) Disruption of maize kernel growth and development by heat stress (role of cytokinin/abscisic acid balance). Plant Physiol 106:45-51

Cleveland WS, Grosse E, Shyu WM (1992) Local regression models. In: Chambers JM, Hastie TJ (ed) Statistical models. S. Wadsworth \& Brooks/Cole, Pacific Grove, CA, p 309-376

DESA (2009) World population prospects: The 2008 revision. United Nations, New York, NY

Engelen-Eigles G, Jones R, Phillips R (2000) DNA endoreduplication in maize endosperm cells: the effect of exposure to short-term high temperature. Plant Cell Environ 23: 657-663

FAO (2010) FAOSTAT. Accessed 25 May. http://faostat.fao. org/default.aspx

- Fischer G, Shah M, Tubiello FN, van Velhuizen H (2005) Socio-economic and climate change impacts on agriculture: an integrated assessment, 1990-2080. Philos Trans R Soc Lond B 360:2067-2083

IPCC (2007) Contribution of working group I to the fourth assessment report of the intergovernmental panel on climate change 2007. Cambridge University Press, Cambridge

Kitagawa G (1998) A self-organizing state-space model. J Am Stat Assoc 93:1203-1215

Koti S, Reddy KR, Kakani V, Zhao D, Gao W (2007) Effects of carbon dioxide, temperature and ultraviolet-b radiation and their interactions on soybean (glycine max l.) growth and development. Environ Exp Bot 60:1-10

Leakey A, Bernacchi C, Dohleman F, Ort D, Long S (2004) 
Will photosynthesis of maize (Zea mays) in the US corn belt increase in future $\left[\mathrm{CO}_{2}\right]$ rich atmospheres? An analysis of diurnal courses of $\left[\mathrm{CO}_{2}\right]$ uptake under free-air concentration enrichment (FACE). Global Change Biol 10: 951-962

Lobell DB, Asner GP (2003) Climate and management contributions to recent trends in U.S. agricultural yields. Science 299:1032

Lobell DB, Field CB (2007) Global scale climate-crop yield relationships and the impacts of recent warming. Environ Res Lett 2:014002

Lobell DB, Cahill KN, Field CB (2007) Historical effects of temperature and precipitation on California crop yields. Clim Change 81:187-203

Lobell DB, Burke MB, Tebaldi C, Mastrandrea MD, Falcon WP, Naylor RL (2008) Prioritizing climate change adaptation needs for food security in 2030. Science 319:607-610

Long SP, Ainsworth EA, Rogers A, Ort DR (2004) Rising atmospheric carbon dioxide: plants FACE the future. Annu Rev Plant Biol 55:591-628

Mall RK, Singh R, Gupta A, Srinivasan G, Rathore LS (2006) Impact of climate challenges on Indian agriculture: a review. Clim Change 78:445-478

Mann CC (1999) Crop scientists seek a new revolution. Science 283:310-314

Monfreda C, Ramankutty N, Foley JA (2008) Farming the planet. 2. Geographic distribution of crop areas, yields, physiological types, and net primary production in the year 2000. Global Biogeochem Cycles 22:GB1022 doi:10. 1029/2007GB002947

Onogi K, Tsutsui J, Koide H, Sakamoto M and others (2007) The JRA-25 reanalysis. J Meteorol Soc Jpn 85:369-432

> Parry M, Rosenzweig C, Livermore M (2005) Climate change, global food supply and risk of hunger. Philos Trans R Soc Lond B 360:2125-2138

Editorial responsibility: Mikhail Semenov,

Harpenden, UK
Porter JR, Semenov MA (2005) Crop responses to climatic variation. Philos Trans R Soc Lond B 360:2021-2035

R Development Core Team (2009) R: A language and environment for statistical computing. R Foundation for Statistical Computing, Vienna

Raftery AE (1995) Bayesian model selection in social research. Sociol Method 25:111-163

Rosegrant MW, Cline SA (2003) Global food security: challenges and policies. Science 302:1917-1919

Sacks WJ, Deryng D, Foley JA, Ramankutty N (2010) Crop planting dates: An analysis of global patterns. Glob Ecol Biogeogr 19:607-620

Schlenker W, Roberts MJ (2009) Nonlinear temperature effects indicate severe damages to U.S. crop yields under climate change. Proc Natl Acad Sci USA 106: 15594-15598

> Siebert S, Döll P, Hoogeveen J, Faures JM, Frenken K, Feick S (2005) Development and validation of the global map of irrigation areas. Hydrol Earth Syst Sci 9:535-547

> Thakur P, Kumar S, Malik JA, Berger JD, Nayyar H (2010) Cold stress effects on reproductive development in grain crops: an overview. Environ Exp Bot 67:429-443

US Census Bureau (2010) World popclock projection. Accessed 25 May. http://www.census.gov/main/www/popclock world.html

USDA (1997) Major world crop areas and climatic profiles (revised) agricultural handbook no. 664. United States Department of Agriculture, Washington, DC

Wilhelm E, Mullen R, Keeling P, Singletary G (1999) Heat stress during grain filling in maize: effects on kernel growth and metabolism. Crop Sci 39:1733-1741

> Yamamura K, Yokozawa M, Nishimori M, Ueda Y, Yokosuka $\mathrm{T}$ (2006) How to analyze long-term insect population dynamics under climate change: 50-year data of three insect pests in paddy fields. Popul Ecol 48:31-48

Submitted: January 24, 2011; Accepted: July 3, 2011 Proofs received from author(s): October 1, 2011 